\title{
3D Modeling for Comparison of Surgically Treated Intracranial Arachnoid Cysts in Children
}

\author{
Jacqueline Boyle BS, Anthony Avellino and Julian Lin* \\ Department of Neurosurgery, University of Illinois College of Medicine at Peoria, USA
}

Received: 阱 August 23, 2018; Published: 制 September 07, 2018

*Corresponding author: Julian Lin, Department of Neurosurgery, University of Illinois College of Medicine at Peoria,530 NE Glen Oak Avenue, Peoria IL 61637, USA

\section{Abstract}

Object: Arachnoid cysts (AC) are benign, fluid-filled lesions of the arachnoid membrane accounting for approximately $1 \%$ of intracranial lesions We utilized 3D volumetric measurement techniques to evaluate $\mathrm{AC}$ volumetric changes with open craniotomy or endoscopic approach for cyst fenestration in pediatric patients, focusing on correlation with patient age, clinical features, and surgical outcomes.

Methods: Pediatric patients ( $\leq 18$ years old) with $\mathrm{AC}$ who had undergone treatment with open craniotomy or endoscopic approach for $\mathrm{AC}$ fenestration were identified from medical records. The volume of the intracranial AC were modeled before and after surgical intervention with Brain Lab software.

Results: Nineteen patients ( 3 females and 16 males) were included (mean age 6.5 \pm 5.5 years; range $0-18$ years). The patients were distributed into three groups based on age: 0-3 years, 3.5-8 years, $\geq 9$ years. Comparison of both pre- and post-operative volumes demonstrated no statistical difference between age groups, but evaluation of percent change between pre- and post-operative volumes revealed statistically significant greater decrease in volume reduction in both older age groups (3.5-8 years and $\geq 9$ years) compared to the youngest age group (0-3 years). There was a trend toward increased improvement/resolution of presenting clinical symptoms with increasing age $(\mathrm{p}=0.01)$. Subdural hematoma was found to be statistically lower in the 3-8 years group $(\mathrm{p}=0.03-0.05)$. Shunt placement was found to be statistically highest in the youngest age group ( $\mathrm{p}=0.03)$.

Conclusion: 3D modeling of surgically treated AC in children provides a consistent quantitative measure to evaluate AC changes over time. Utilizing comparison by age, this study finds significantly greater decreases in cyst volume and greater post-surgical symptom improvement/ resolution with cyst fenestration in older pediatric patients, suggesting support for surgical intervention in these patients. In young children, especially infants, changes in CSF dynamics result in minimal cyst decrease following fenestration and a significant role for shunts.

\section{Introduction}

Arachnoid cysts (AC) are benign, fluid-filled lesions of the arachnoid membrane, most often congenital, accounting for approximately $1 \%$ of intracranial lesions. AC are most commonly located in the middle cranial fossa (MCFAC) [1-3]. AC typically remain stable, but spontaneous disappearance and growth has been noted [4], as well as rupture into the subdural, extradural, or intracystic space [1-5]. While many ACs remain asymptomatic, general symptoms can include headache, hydrocephalus, skull deformities, macrocrania, focal neurologic disorders, endocrine dysfunction, and cognitive disorders [6-9]. Despite the number of retrospective studies, there continues to be no consensus among neurosurgeons for surgical treatment of AC, though a majority favor limiting surgical treatment to clinically symptomatic cases [2,7,912]. Previous work utilizing 3D modeling in AC has been limited in follow-up, and objective patient improvement correlated to cyst size has been inconclusive $[13,14]$.

In this retrospective study of 19 pediatric patients with $\mathrm{AC}$, we utilized 3D volumetric measurement techniques to evaluate $\mathrm{AC}$ volumetric changes with open craniotomy or endoscopic approach for cyst fenestration, focusing on correlation with patient age, clinical features, and surgical outcomes.

\section{Methods \\ Patients}

Pediatric patients ( $\leq 18$ years old) were identified from the records of OSF St. Francis Hospital as having undergone treatment with open craniotomy or endoscopic approach for AC fenestration between January 2008-December 2015. Patients were required to have both pre-operative and post-operative magnetic resonance imaging (MRI) or computed tomography (CT) scans available for image processing. Patients with other known intracranial developmental anomalies (ex: Dandy-Walker, Chiari malformation) were not included in the study. There were no restrictions on the anatomical location of the AC. Age, sex, clinical features (pre- and post-operative), and post-operative outcomes (i.e.: post-operative shunting) were obtained from the medical records. We obtained permission from the University of Illinois College of Medicine at Peoria IRB prior to starting this study.

\section{Surgical Procedure}

A skin incision was made in front of the ear to approximately 3 cm superiorly, and a burr hole was made in a location overlying the cyst determined by prior image planning. Once the dura was opened 
and pia was coagulated, a rigid neuroendoscope was introduced directly into the cyst with the endoscopic fenestration technique. Open craniotomy with microscope was also utilized. After establishing the anatomy, blunt dissection was used to fenestrate the wall of the cyst to allow for free communication of the cyst with the ventricular system (cystoventriculostomy) through the lateral and/or the third ventricle. After confirmed hemostasis of the area, the dura mater was sutured, and the skin was closed in two layers.

\section{D Volumetric Measurement}

Tumor volumes were calculated using Brain Lab software (Brain lab, Feldkirchen, Germany) with the Smart brush element for detection of anatomical edges of the user-designated AC.

\section{Statistical Analysis}

The data is shown as a mean \pm standard deviation (SD). Statistical differences between groups with continuous variables were compared using 1-way ANOVA t tests. Statistical difference between groups with binary variables $(\mathrm{Y} / \mathrm{N}$, sex) were compared using Chi-squared test. Statistical significance was set at $\mathrm{p} \leq 0.05$.

\section{Results}

\section{Patients}

Nineteen patients ( 3 females and 16 males) were included (mean age $6.5 \pm 5.5$ years; range 0 -18 years) with the following distribution of AC anatomical location: left middle fossa (10), right middle fossa (6), suprasellar (1), frontal convexity (1), left ventricular (1). The patients were distributed into three groups based on age: 0 - 3 years $(1.65 \pm 1.2$ years), 3.5 -8 years $(5.33 \pm 1.9$ years), $\geq 9$ years ( $13.3 \pm 3.5$ years). Age group differences were found to statistically significant $(\mathrm{p}=<0.0001-0.3$ ). There was no statistical difference in sex distribution among the groups $(p=0.15-0.60)$ (Figures 1-2).

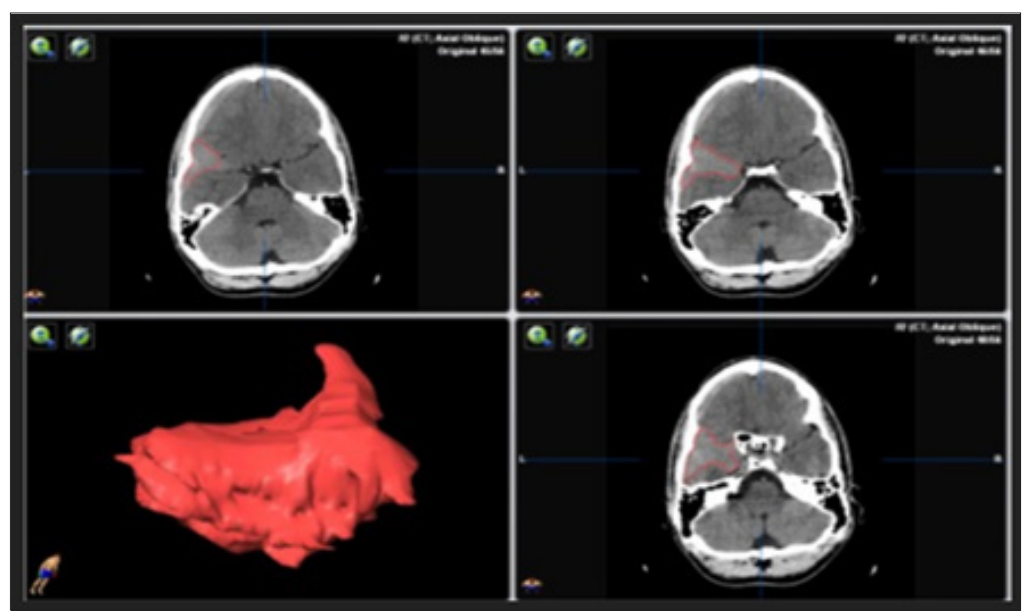

Figure 1: Brain Lab software rendering of a right middle fossa arachnoid cyst with corresponding outline in consecutive axial MRI slices.

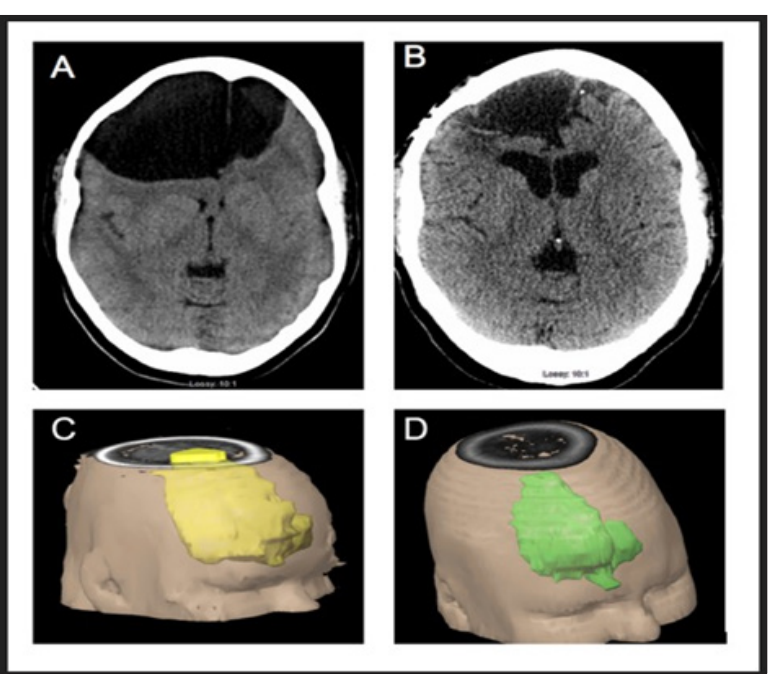

Figure 2: Pre-operative (A) and post-operative (B) MRI with respective pre-operative (C) and post-operative (D) BrainLab rendering of the arachnoid cyst. 


\section{Volumetric Findings}

Comparison of both pre- and post-operative volumes demonstrated no statistical difference between age groups (03: $78.08 \pm 99.7,61.4 \pm 78.7 ; \quad 3.5-8: 35.53 \pm 14.2, \quad 19.09 \pm 9.4 ; \quad \geq 9$ : $35.52 \pm 33.9,17.22 \pm 21.5$ ) with $\mathrm{p}=0.28->0.99$. Evaluation of percent change between pre- and post-operative volumes revealed statistically significant greater decrease in volume reduction in both older age groups (3.5-8: $-44.81 \pm 33.8, p=0.04 ; \geq 9$ : $-55.68 \pm 15.6$, $\mathrm{p}=0.009)$ compared to the youngest age group $(-9.05 \pm 20.6 \%)$. Shorter follow-up ( $<5$ months) was done only in patients with postoperative shunting to treat symptomatic increased intracranial pressures (Figure 3).

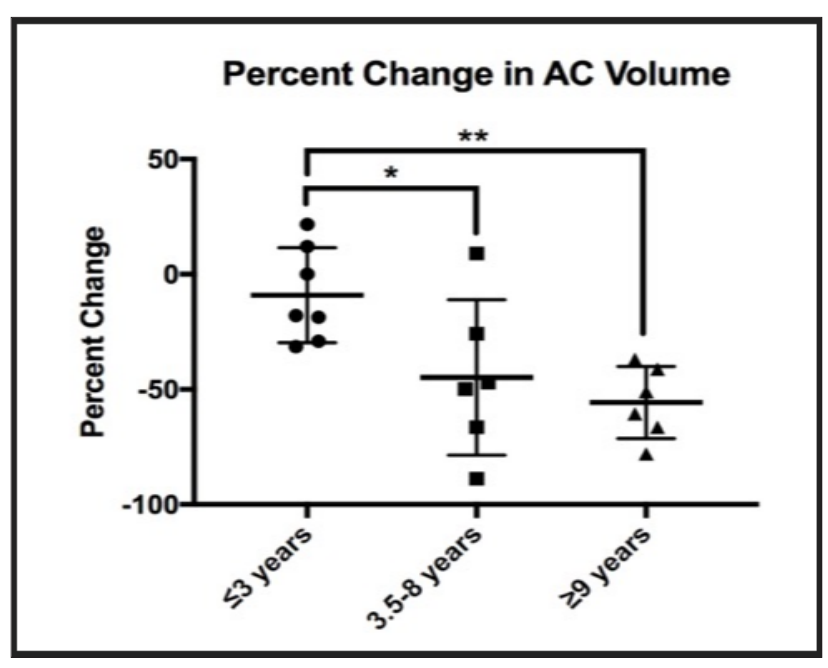

Figure 3: Pre-operative to post-operative percent change in arachnoid cyst volume by age groups.

\section{Clinical Findings}

The most common presenting clinical symptom was headache ( $9 / 19$ patients). All patients in the oldest age group ( $\geq 9$ years) presented with headache as the primary complaint. The two youngest patients (newborn and 3 months) presented with hydrocephalus. Other presenting symptoms included discongujage gaze (1/19), subdural hematoma following fall (1/19), skull abnormalities (2/19), seizure (3/19), and developmental delay $(1 / 19)$. Post-fenestration revealed varied improvement or resolution of symptoms across age groups. There was a trend toward increased improvement/resolution of presenting clinical symptoms with increasing age $(14.2 \%, 33.3 \%, 83.3 \%)$ with statistical significance between the youngest and oldest age groups $(\mathrm{p}=0.01)$. Subdural hematoma was found to be statistically lower in the 3-8 years group (16.7\%) compared to the 0 -3 years $(57.1 \%$, $\mathrm{p}=0.03)$ and the $\geq 9$ years $(50 \%, \mathrm{p}=0.05)$ groups. Shunt placement after AC fenestration surgery demonstrated increasing rates of shunts with increasing age. The youngest patients had a $57.1 \%$ of shunt placement compared to no shunts in the oldest patients $(\mathrm{p}=0.03)$.

\section{Discussion}

To our knowledge, a retrospective study of $\mathrm{AC}$ has yet to utilize volumetric and clinical analysis for comparison of pediatric patients by age group. AC are classified based on their anatomical location within the intracranial space. MCFAC are additionally grouped into Galassi classifications (Type I-III) based upon the shape, displacement of the brain, and communication with the subarachnoid space [3]. With advancements in 3D image modeling, it is now possible to create computer-assisted 3D structures for more precise structure and volume measurements compared to traditional 2D measurements and subjective classification. Additional use of the Smart brush tool in the Brain Lab software, as utilized in this study, may offer greater consistency in volume measurement among users, as contours are computer defined once an area is selected.

Although the patients of this study did not uniformly undergo one surgical fenestration technique (open craniotomy and endoscopic), comparison of surgical approaches for AC treatment (open craniotomy for cyst excision, open craniotomy for cyst fenestration, endoscopic cyst fenestration, and cystoperitoneal shunting) have yielded no differences in outcomes and remain open to surgeon preference [15].

In this study cohort, improvement/resolution of symptoms with AC fenestration was lower compared to other similar studies studies (42.1\%), although not outside what would be expected with qualitative clinical measures (range: 48-92.5\%) [7,12,16,17]. When the patients were distributed by statistically different age groups, a trend emerged with increased improvement of clinical presentation with increasing age. Those pediatric patients $\geq 9$ demonstrated statistically significant improvement/resolution of both presenting clinical symptoms (83.3\% v. 14.3\%) and reduction of cyst volume $(-55.68 \pm 15.6$ v. $-9.05 \pm 20.6 \%, p=0.009)$, emphasizing the value of cyst fenestration in older pediatric patients. While there are reports of correlation between volumetric change in AC and symptoms, this claim does not demonstrate consistency among studies. This study supports a correlation between increased symptom improvement with increased cyst reduction among our oldest patient's cohort.

Further evaluation of clinical symptoms in this cohort demonstrated a number of post-operatively placed ventriculoperitoneal shunts (VP) to treat increased ICP, primarily in patients 3 years 
and younger. Similar development of "communicating hydrocephalus" post-fenestration and increased rates of shunts in AC patients 2 years and younger has been reported $[13,18]$. This trend of post-operative shunt placement, the statistically smallest decrease in AC volume, and lowest rates of symptoms improvement (14.2\%) of patients 3 years and younger suggests craniotomy or endoscopic fenestration of AC may not be the superior choice of treatment at this age. Yet, shunt failure, unexpected hemorrhage, infection, and life- long shunt dependence complicate the decision to utilize these shunts as the first treatment method in young patients [15].

Other notable clinical findings were the presence of seizures as a presenting symptom only within our 3.5-8 years age group ( $50 \%$ prevalence). None of these patients experienced changes in their seizures after surgical intervention. The relationship between AC location and/or presence and seizures is controversial, as no correlations have yet to me made. A similar lack of correlation between seizure resolution and AC location or volume change was present in this study $[16,19,20]$. In concordance with other reports, this study demonstrated increased prevalence (83.3\%) of subdural hematomas in young males, particularly in the $\geq 9$ years group of this study, supporting consistent monitoring of these patients after surgical treatment [21].

\section{Conclusion}

3D modeling of surgically treated AC provides a consistent quantitative measure to evaluate $\mathrm{AC}$ changes over time. Utilizing comparison by age, this study finds significantly greater decreases in cyst volume and greater post-surgical symptom improvement/ resolution with cyst fenestration in older pediatric patients, suggesting support for surgical intervention in these patients. In young children, especially infants, changes in CSF dynamics result in minimal cyst decrease following fenestration and a significant role for shunts.

\section{Disclosures}

The authors report no conflict of interest concerning the materials or methods used in this study or the findings specified in this paper.

\section{References}

1. Al-Holou WN, Terman S, Kilburg C, Garton HJ, Muraszko KM, et al. (2013) Prevalence and natural history of arachnoid cysts in adults. J Neurosurg 118(2): 222-231.

2. Cincu R, Agrawal A, Eiras J (2007) Intracranial arachnoid cysts: Current concepts and treatment alternatives. Clin Neurol Neurosurg 109(10): 837-843.

3. Galassi E, Piazza G, Gaist G, Frank F (1980) Arachnoid cysts of the middle cranial fossa: A clinical and radiological study of 25 cases treated surgically. Surg Neurol 14(3): 211-219.

4. Russo N, Domenicucci M, Beccaglia MR, Santoro A (2008) Spontaneous reduction of intracranial arachnoid cysts: A complete review. Br J Neurosurg 22(5): 626-629.
5. Huang D, Abe T, Kojima K, Tanaka N, Watauabe M, et al. (1999) Intracystic hemorrhage of the middle fossa arachnoid cyst and subdural hematoma caused by ruptured middle cerebral artery aneurysm. AJNR Am J Neuroradiol 20(7): 1284-1286.

6. Gosalakkal JA (2002) Intracranial Arachnoid Cysts in Children: A Review of Pathogenesis, Clinical Features and Management. Pediatr Neurol 26(2): 93-98.

7. Christian A Helland, Knut Wester (2007) A population based study of intracranial arachnoid cysts: Clinical and neuroimaging outcomes following surgical cyst decompression in adults. J Neurol Neurosurg Psychiatry 78(10): 1129-1135.

8. Raeder MB, Helland CA, Hugdahl K, Wester K (2005) Arachnoid cysts cause cognitive deficits that improve after surgery. Neurology 64(1): 160-162.

9. Mørkve SH, Helland CA, Amus J, Lund-Johansen M, Wester KG (2016) Surgical Decompression of Arachnoid Cysts Leads to Improved Quality of Life: A Prospective Study. Neurosurgery 78(5): 613-625.

10. Wang Y, Wang F, Yu M, Wang W (2015) Clinical and radiological outcomes of surgical treatment for symptomatic arachnoid cysts in adults. J Clin Neurosci 22(9): 1456-1461.

11. Ali ZS, Lang SS, Bakar D, Storm PB, Stein SC (2014) Pediatric intracranial arachnoid cysts: Comparative effectiveness of surgical treatment options. Childs Nerv Syst 30(3): 461-469.

12. Spacca B, Kandasamy J, Mallucci CL, Genitori L (2010) Endoscopic treatment of middle fossa arachnoid cysts: A series of 40 patients treated endoscopically in two centres. Childs Nerv Syst 26(2): 163-172.

13. Li Y, Chen X, Xu B (2014) The efficacy of neuroendoscopic treatment for middle cranial fossa rachnoid cysts assessed by MRI 3D segmentation and modeling. Childs Nerv Syst 30(6): 1037-1044.

14. Rabiei K, Högfeldt MJ, Doria-Medina R, Tisell M (2016) Surgery for intracranial arachnoid cysts in children-a prospective long-term study. Childs Nerv Syst 32(7): 1257-1263.

15. Ali M, Bennardo M, Almenawer SA, Zagzoog N, Smith AA, et al. (2015) Exploring predictors of surgery and comparing operative treatment approaches for pediatric intracranial arachnoid cysts: A case series of 83 patients. J Neurosurg Pediatr 16(3): 275-282.

16. Rabiei K, Jaraj D, Marlow T, Jensen C, Skoog I, et al. (2016) Prevalence and symptoms of intracranial arachnoid cysts: A population-based study. J Neurol 263(4): 689-694.

17. Okano A, Ogiwara H (2016) The effectiveness of microsurgical fenestration for middle fossa arachnoid cysts in children. Childs Nerv Syst 32(1): 153-158.

18. Choi JW, Lee JY, Phi JH, Kim SK, Wang KC (2015) Stricter indications are recommended for fenestration surgery in intracranial arachnoid cysts of children. Childs Nerv Syst 31(1): 77-86.

19. Li L Zhang Y, Li Y, Zhai X, Zhou Y, Liang P (2013) The clinical classification and treatment of middle cranial fossa arachnoid cysts in children. Clin Neurol Neurosurg 115(4): 411-418.

20. Arroyo S, Santamaria J (1997) What is the relationship between arachnoid cysts and seizure foci? Epilepsia 38(10): 1098-1102.

21. Adin ME, Yildiz MS, Deniz MA, Behzadi AH, Mata-Mbemba D (2018) Arachnoid cysts with spontaneous intracystic hemorrhage and associated subdural hematoma: Report of management and follow-up of 2 cases. Radiology Case Reports 13(2): 516-521. 


\section{ISSN: 2574-1241}

DOI: 10.26717/BJSTR.2018.08.001705

Julian Lin. Biomed J Sci \& Tech Res

(c) (9) This work is licensed under Creative

Submission Link: https://biomedres.us/submit-manuscript.php

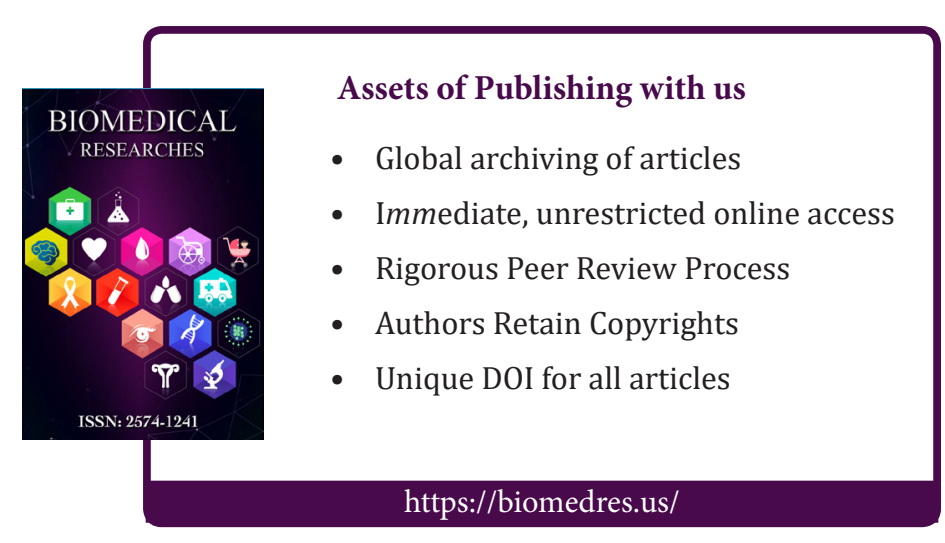

